\title{
Hot talent, high performance, and bags of money - and that's just the UKSEM speaker list!
}

\author{
Andrew Franklyn-Miller
}

Daniel Coyle in The Talent Code 1 talks of hotbeds of talent such as Spartak Tennis Club in Moscow and the 'footsal' fields of Sao Paulo producing talent well in excess of expectations. He extends the story to Florence in the Renaissance from which came Michelangelo, Dante, Leonardo da Vinci and Galileo - a remarkable pool of excellence! There are certain centres in the world, where a collection of factors combine to make them special, whether it be coaching, learning, drive, ambition or just something in the water.

There are also hotbeds of sport and exercise medicine talent such as the Centre for Health, Exercise and Sports Medicine, University of Melbourne and the Oslo Sports Trauma Centre, Norway (http://www.ostrc.no). Here, a collection of individuals including Roald Bahr and Lars Engebretsen along with Paul McCrory and Kim Bennell with international colleagues have inspired, driven and rolled out significant work, much greater than larger institutes because the "climate is right'. In the UK, we are perhaps yet to find the right climate, but the time is surely now in the build up to the London 2012 Games.

When the British Association of Sport and Exercise Medicine launched UKSEM, its interdisciplinary world class sports and exercise medicine conference in 2010, the aim was to create a world class event by bringing together not just physicians, but the full multidisciplinary team including coaches, athletes, conditioners, physiotherapists and soft tissue therapists among many. The aim was to re-create that climate of talent, to build performance not just in the athlete, but in the whole support staff, to find answers, challenge concepts and new solutions. London 2010 was a great success with 700 delegates and 100 speakers in Sport and Exercise

Correspondence to Andrew Franklyn-Miller, Head of Research and Director of UKSEM, Centre of Human Performance, Rehabilitation and Sports Medicine, DMRC, Headley Court, Epsom, Surrey KT18 6JX UK; afranklynmiller@me.com from all over the world. 2011 launches new innovations such as installment payments, new updated AV and lecture halls, in seat voting and feedback, a conference iphone and ipad app, and the ASICS exhibition hall.

In a first for a Sports Medicine conference, ASICS are building an indoor $200 \mathrm{~m}$ running track, a fencing salle, a boxing ring and wrestling arena, and weightlifting platform, all sports that will be hosted at ExCeL in 2012 at the Olympics. Athlete demonstrations and workshops with biomechanists and coaches such as the Russian wrestling team and the French fencers alongside world-class track and field stars will be able to interact with delegates on a personal level. All this around the exhibition space where over 1000 delegates can network and mingle and germinate a hotbed of talent in London.

One of these such centres is the Centre for Human Movement Studies at the University of Groningen, The Netherlands. Michel Brink wrote on monitoring overreaching in stress and recovery in talented adolescents, ${ }^{2}$ but particularly it is their biomechanical work on injury in a particular biomechanical patellar tendon work ${ }^{3}$ and the physiological skills in developing endurance in talented youngsters which is impressive. ${ }^{4}$ Here, much pioneering work on talent identification and early identification of height, stature and competence has been done as Marije Elferink-Gemser highlights (see page 683), but 55 papers in BJSM alone is no mean feat. Grant Tomkinson discusses an excellent study on aerobic levels for health in adolescents (see page 686).

One of the areas of 2011 already topical is that of movement control in sport and rehabilitation - a commonly used buzzword in my practice but with differing meanings to many. There sometimes is no need to overcomplicate it and Kelvin Giles, Track and Field coach, educator and former Head of Performance at the Australian Institute of Sport describes it well (see page 684). There are many parallels in movement, kinetic and athletic control and increasing bodies of work being produced to validate these as outcome measures, rehabilitation tools and performance training as featured in abstracts at the International Olympic Committee World Conference. ${ }^{5}$ The concepts of movement coordination are certainly central to rehabilitation, but may well underpin injury prevention mechanisms in the first instance. Fédération Internationale de Football Association (FIFA) and the Rugby Football Union (RFU) are doing a great work in injury tracking, ${ }^{6}$ to identify injury mechanisms, trends and focus interventions but FIFA has with 11+, a movement-based warm up, designed specifically for football, made great strides into prevention, ${ }^{7}$ again with a fantastic piece of work from Astrid Junge and colleagues. She will speak at UKSEM and with the focus on early talent identification clearly more work is needed on the injury risk in adolescent athletes to design sport-specific intervention strategies. ${ }^{3} 8$ Two articles on comparing contact with non-contact injuries in hamstrings (see page 709) and ankle injuries in football academies (see page 702) highlight important work being done.

The other hot topic of 2011, surely to hit the headlines is the one of barefoot running. Following the lead from the BJSM, UKSEM has an active twitter following and debate has been raging on twitter, @ PrimalfootOrg and @runnaturally,which is worth a look, and its biggest proponent Prof Daniel E Lieberman from Harvard has a site http://www.barefootrunning. fas.harvard.edu/ that explains the basics.

Is barefoot running just injury waiting to happen, which will fill our clinics in the coming months or is it a panacea to the overuse injuries we all are so familiar with? We look at gait retraining that dovetails well with barefoot running theory (see page 691). How this fits with the use of orthoses over many years is but one of many unanswered questions and Christian Barton's study in this issue highlights the effect of orthoses outcome on specific gait-related abnormalities (see page 697), but this may be at odds with (see page 743) a meta-analysis of the effects of foot control. This is sure up for debate when Professor Lieberman, Beno Nigg, Simon Bartold and Sharon Dixon take the floor at UKSEM in November when ASICS will host a debate on the way forward.

One voice I am looking forward to hearing is another twitter follower and an avid blogger Dr Ross Tucker@ScienceofSport from Cape Town, South Africa who last 
wrote in this journal on the physiological basis of pacing ${ }^{9}$ but runs the fantastic education resource of http://www.sportsscientists.com, a must for anyone working in elite or non-elite sport. He is delivering an overview of physiological performance at UKSEM and also a few workshops on various topics, which no doubt will book very quickly both in the limits of human performance, pacing and recovery methods.

Coaching a sport at the weekend for fun, such as our children's Tag or Mini Rugby, and a career in professional coaching, although they have the same origins, take very different paths. The Head of Elite Coaching for the RFU and I discussed this very path last month, and identified the stresses and also the need to understand a great deal about all aspects of the interdisciplinary team so they can make informed decisions about our interventions. We have a dedicated strand at this year's conference where world class international coaches of some of the world's greatest athletes will talk about how they deliver, alongside psychologists, business leaders and winners about composing the team. The names of these will be announced in due course on http://www. uksem.org.

Now to the money! Dr John Orchard wrote an editorial on the MoneyBall approach in $2009^{10}$ and suggested this approach may pay dividends. An analogy I use is would you take your Maserati to the local garage and ask them to take a look, or to the specialist dealer who is offering a 'world-class service'? Which costs more, but offers best value in the end? Well, Damien Commoli, Director of Football at Liverpool FC, will speak on just this in November about assembling a world class team and Dr Peter Brukner, Head of Medicine and Science, will add his thoughts in a panel discussion with a Football agent and Mary O'Rourke, $\mathrm{QC}$ of the General Medical Council on Money Ball.

With London 2012 around the corner, I cannot end this warm up without the mention of both Olympic and Winter Olympic sports focussed on athlete demonstrations and many eminent names from the Olympic sports medicine, Per Renstom, Finch, Pluim, Turner, McDonagh and also Head coaches of UK athletics Charles van Commenee, Steve Gunn of GB Rowing and Gary Anderson of GB Bobsleigh, a feast of information.

Join us in London on 23-26 November for a taste of London before the Games, perhaps visit the ATP Tennis Masters at the $\mathrm{O} 2$ Arena or engage in a little preChristmas shopping or take in the dual stream main programmes with concurrent sessions with the Association of Charted Sports Physiotherapists, Defense Rehabilitation Conference, the British Association of Sport Rehabilitation trainers, UKSCA and others.

(The names in bold highlight those speaking at the UKSEM in November.)

Competing interests AFM is Chair of BASEM

Education and Director of UKSEM and has devotion but no financial interest in its success.
Provenance and peer review Commissioned; internally peer reviewed.

Accepted 19 May 2011

Br J Sports Med 2011;45:681-682

doi:10.1136/bjsports-2011-090239

\section{REFERENCES}

1. Coyle D. The Talent Code: Greatness isn't born. It's grown. Paperback: 256 pages. Arrow, London. ISBN: 0099519852.

2. Brink MS, Visscher C, Arends S, et al. Monitoring stress and recovery: new insights for the prevention of injuries and illnesses in elite youth soccer players. Br J Sports Med 2010;44:809-15.

3. Bisseling RW, Hof AL, Bredeweg SW, et al. Are the take-off and landing phase dynamics of the volleyball spike jump related to patellar tendinopathy? Br J Sports Med 2008;42:483-9.

4. Elferink-Gemser MT, Visscher C, van Duijn MA, et al. Development of the interval endurance capacity in elite and sub-elite youth field hockey players. Br J Sports Med 2006;40:340-5.

5. Shultz R, Mooney K, Anderson S, et al. Functional movement screen: inter-rater and subject reliability. Br J Sports Med 2011;45:374.

6. van Mechelen W, Collard DCM, M Chinapaw, et al. Magnitude and economic burden of sports and physical activity-related injuries in dutch 10-12 year old children. Br J Sports Med 2011;45:313 doi:10.1136/bjsm.2011.084038.9

7. Saho Y, Suzuki T, Setojima M, et al. The efficacy of the 11 and the $11+$ in injury prevention and physical fitness improvement on male collegiate football teams. Br J Sports Med 2011;45:313 doi:10.1136/bjsm.2011.084038.10

8. Steffen K, Engebretsen L. More data needed on injury risk among young elite athletes. $\mathrm{Br} J$ Sports Med 2010;44:485-9.

9. Tucker $\mathbf{R}$. The anticipatory regulation of performance: the physiological basis for pacing strategies and the development of a perception-based model for exercise performance. Br J Sports Med 2009;43:392-400.

10. Orchard JW. On the value of team medical staff: can the "Moneyball" approach be applied to injuries in professional football? Br J Sports Med 2009; 43:963-5. 